\title{
Tras las huellas de Sadako. El espectro de la literatura llevado al cine
}

\author{
In the footsteps of Sadako. \\ The spectrum of literature taken to the cinema
}

\author{
Antonio Míguez Santa Cruz \\ Universidad de Córdoba \\ gesto_tecnico@hotmail.com \\ ORCID ID: 0000-0001-7610-5616
}

Resumen: A finales del siglo pasado el llamado J-horror (Japanese horror) revolucionó a nivel global el género de terror cinematográfico debido al éxito alcanzado por Ringu (Hideo Nakata, 1998). Como es natural cuando una película innova tan exitosamente, un enorme caudal de producciones deudoras inundó las pantallas de todo el mundo intentando emularla. Sin embargo, Sadako, el archiconocido fantasma del cine, procedía en realidad de una novela escrita en 1991 por Koji Suzuki. Nuestro cometido en este artículo será ahondar en los mecanismos que explican este trasvase entre literatura y cine, tocando aspectos clave como la experiencia vital de Nakata a la hora de realizar su adaptación, o por qué razones la novela original no debe considerarse dentro del género J- horror.

Palabras clave: Literatura, Cine, Adaptación cinematográfica, Koji Suzuki, Hideo Nakata, Ringu, Jhorror.

\begin{abstract}
At the end of the last century the so-called J-horror (Japanese horror) revolutionized the genre of film horror globally due to the success achieved by Ringu (Hideo Nakata, 1998). Naturally, when a film innovates so successfully, a huge flow of debtor productions flooded the screens around the world trying to emulate it. However, Sadako, the well-known movie ghost, actually came from a novel written in 1991 by Koji Suzuki. Our task in this article will be to delve into the mechanisms that explain this transfer between literature and cinema, touching key aspects such as Nakata's vital experience when he filmed his adaptation, or for what reasons the original novel should not be considered within the $J$-horror genre.
\end{abstract}

Key Words: Literature, Cinema, Film Adaptation, Koji Suzuki, Hideo Nakata, Ringu, J-horror. 


\section{INTRO Y CONTAGIO}

El año, 1998. Fue entonces cuando el terror cinematográfico alumbró a una de sus más influyentes criaturas, para de paso reactivarse en una década excesivamente dependiente del slasher americano. Hablamos por supuesto de Ringu (Hideo Nakata), que veintiún años después de su estreno aún permanece como la película japonesa de imagen real más taquillera en la historia del sol naciente. Lejos de limitarse a su país, la novedosa propuesta traspasaría fronteras hasta el punto de cosechar varios premios internacionales, entre los que podemos destacar el alcanzado en el Festival de Cine Fantástico de Sitges, allá por 1999.

Como suele ocurrir con las películas hito, un auténtico goteo de producciones deudoras inundaría las salas de los cinco continentes, en un proceso tan intenso como breve si hablamos de aportes dotados de una verdadera calidad. No obstante, ahí dejaron su impronta Dark Water (Hideo Nakata, 2002), La maldición (Takashi Shimizu, 2002), Dos Hermanas (Kim Jee-woon, 2003) o Shutter (Banjong Pisanthanakun, 2004) como abanderados de un ejército de clones de Sadako, lo que nos da una medida de hasta qué punto Ringu se ha llegado a fusionar con la cultura pop. Y es que actualmente no es extraño encontrar videojuegos y mangas inspirados en la obra de Nakata, memes de la chica del pozo circulando por la red, cuando no gente cosplayeada de yürei ('fantasma japonés'), mimetizándose entre Drácula, Michael Myers, Freddy Krueger o Pinhead durante las festividades de Halloween.

Ahora bien, la culpable de aquella $j$-horror wave, Ringu, era en realidad la reescritura fílmica de una novela publicada en 1991 por Koji Suzuki, conocido popularmente como el Stephen King nipón. Por tanto, siendo esta una revista llamada Trasvases entre la literatura y el cine, sería honesto acudir en primer lugar al texto matriz con motivo de analizar el trasvase, pese a que fuese la pantalla y no el papel el gran difusor de Sadako entre el público. Al igual que ocurre en la ficción, por cierto.

\section{RINGU DE KoJI SUZUKI}

Probablemente en Japón exista uno de los bestiarios más ricos de todas las mitologías conocidas. Esa circunstancia no es una anécdota, pues los nipones conviven mezclando la tecnología más puntera con costumbres milenarias fruto de la creencia en el más allá. Naturalmente, la tendencia se ha visto reflejada en el mundo de las artes o la literatura, y paradigma de ello son los preciosos grabados de Sekien Toriyama o la gran inclinación hacia lo sobrenatural en los diversos tipos de teatro de aquel país. Como era de esperar, también multitud de literatos han revisado el relato de temática fantástica hasta convertirlo en un formato elevado y de gran éxito; ahí están Akinari Ueda con su Luna de las lluvias, Koizumi 
Yakumo con su Kwaidan o Ango Sakaguchi con su Bosque bajo los cerezos en flor como ejemplos para demostrarlo.

Koji Suzuki, por tanto, no es sino un eslabón más de esa cadena que une el Tokio de los neones y los rascacielos con el atávico relatario fantasmal del archipiélago. Nuestro hombre nace en Hamamatsu, ciudad perteneciente a la prefectura de Shizuoka, en mayo de 1957. Tras graduarse en la universidad de Keio llegó a impartir clases de literatura francesa, sintiéndose especialmente atraído por la obra de Guy de Maupassant (Suzuki, 2015: 2). Ya en 1990 se consagraría como escritor tras el éxito de su novela Paraíso, aunque fue al año siguiente con The Ring ${ }^{1}$ cuando estampó su nombre con filigrana de oro en la historia de la literatura japonesa.

El relato comienza con Tomoko, una estudiante de último curso de instituto, preparando un examen de recuperación a comienzos de septiembre. La joven se encontraba sola porque sus padres habían reservado entradas para un partido de béisbol esa misma noche. De pronto, después de sentir una atmósfera malsana, percibió una presencia a sus espaldas que expelía un desagradable olor a podrido. Como el lector podrá suponer, Tomoko fue hallada muerta debido a un presunto paro cardiaco y con una terrible mueca de espanto articulándole el rostro. Apenas unos días después el periodista Kazuyuki Asakawa, tío de la fallecida, descubrió en una conversación de taxi que otro chico murió a la misma hora que su sobrina, lo cual iniciaría unas pesquisas que desembocarían en el hallazgo de otros dos fallecidos en idénticas circunstancias.

Aparentemente sin nada en común, las cuatro víctimas debían de estar, sin embargo, relacionadas de algún modo. Así se confirmó cuando Asakawa encontró en la chaqueta de Tomoko el flyer de un complejo de ocio llamado Hakone Pacific Land, donde los adolescentes pasaron una noche en el bungalow B4. Una vez en la recepción del complejo turístico, nuestro protagonista reparó en una cinta sin cubierta colocada entre decenas de películas a disposición de los usuarios. Dejándose llevar por su intuición la llevó a la habitación B4 y se dispuso a reproducirla en el video; el contenido consistía en una sucesión de colores alternándose con una serie de escenas a priori sin sentido. Entre ellas destacaban la de una anciana hablando en un singular dialecto, lo que parecía ser un volcán en erupción, un neonato y un hombre herido abalanzándose sobre la pantalla, todo ello sembrado de fundidos en negro separados en pequeños

\footnotetext{
${ }^{1}$ En adelante, nos referiremos a la novela de Suzuki como The Ring (título con el que es conocida tanto en el ámbito anglosajón como en el hispánico) y a la película de Nakata como Ringu para diferenciarlas bien.
} 
intervalos. Concluyendo la cinta se decía que quien la hubiese contemplado moriría transcurrida una semana. Al parecer, existía una forma de romper el maleficio, si bien fue imposible conocerla debido a que Tomoko y sus acompañantes borraron el fragmento a modo de chanza.

Asakawa nunca fue un escéptico, pero ni él mismo hubiera creído la historia de la maldición del video de no ser por la desaparición de sus anteriores espectadores, así como por imposibles sensaciones físicas padecidas durante el visionado, como fue el hecho de experimentar el peso y la lubricidad de un recién nacido entre los brazos justo cuando la criatura apareció en pantalla. Angustiado y sin saber muy bien qué hacer, el protagonista buscó la ayuda de Ryuji Takayama, un sociópata profesor adjunto de universidad sobre el que pesaba la sombra de una violación cometida en juventud. Ryuji visionó una copia de la cinta, sellando su destino al de Kazuyuki y convirtiéndose en el verdadero motor de toda acción. De hecho fue él quien descubrió que los fundidos en negro eran parpadeos, por lo que la mayor parte de las escenas eran en realidad fruto de la visión subjetiva de alguien provisto, sin duda, de grandes poderes psíquicos. Para desgracia de Asakawa, Shizuka y Yoko, esposa e hija respectivamente, cayeron también bajo la maldición del video debido a un funesto giro de los acontecimientos.

El siguiente paso lo daría de nuevo Ryuji, conduciendo a su amigo a un ryokan/museo regentado por el hijo de un antiguo académico llamado Miura. Profesor universitario especializado en parasicología, la empresa de su vida consistió en aglutinar información sobre individuos con poderes telequinéticos. Entre los miles de expedientes del archivo de Miura llamó la atención el de una niña llamada Sadako, quien vaticinó la erupción de un volcán situado en una isla apartada de Honshu. Ryuji consiguió localizar el emplazamiento al relacionarlo con el dialecto hablado por la anciana gracias a una compañera lingüista de su Facultad. Una vez allí, supieron el fatal destino de Shizuko, la progenitora de Sadako: incapaz de soportar la presión de los medios de comunicación se suicidó arrojándose a las entrañas del volcán, por lo que su hija quedó al cuidado del padrastro. Este enfermaría de tuberculosis unos años más tarde, ingresando en un complejo sanitario que andando el tiempo llegaría a ser el Hakone Pacific Land.

Poco a poco los protagonistas fueron consiguiendo más información sobre Sadako, quien antes de cumplir dieciocho años se enrolaría en una compañía de teatro. Para su desgracia, la desaparición en extrañas circunstancias de un miembro del grupo escénico ocasionó su salida, primera piedra de una serie de desdichas que culminarían con su violación y asesinato a manos de un doctor durante una de las frecuentes visitas a su padre. Llamado Nagao, formaba parte de la plantilla del hospital para 
tuberculosos, pero en aquel momento se encontraba de baja por haber contraído la viruela. Tanto Asakawa como Ryuji supusieron que se trataba del hombre que aparecía durante el video, así que se desplazaron hacia su consulta privada con el objetivo de interrogarlo. Allí, bajo coacción, confesó que esparció los restos de Sadako en el interior de un pozo de la zona, además de revelar la naturaleza hermafrodita de su víctima. A pocas horas del final de la cuenta atrás, los protagonistas encontraron el pozo en el entresuelo del bungalow B4, exhumando a continuación el esqueleto de Sadako. ¿Se apaciguaría su espíritu vengativo devolviendo sus huesos a los Yamamura? Ryuji murió al día siguiente a manos del fantasma, pero antes de fallecer consiguió averiguar la clave para salvar de la maldición a la familia de Asakawa. Ya en forma de espectro, hizo entender a su amigo la necesidad de realizar una copia de la cinta y enseñársela a otro espectador, ampliando el círculo maldito de Sadako.

\section{HideO NAKATA}

Okayama, 1961. Nace Hideo Nakata, quien con el tiempo estudiaría cinematografía en la universidad de Tokio. Por derecho propio pertenece a aquella generación de directores nacida después de la II Guerra Mundial que tanto ha cambiado el estilo cinematográfico en Japón. El camaleónico Takeshi Kitano (1947) se erigió en uno de los primeros creadores capaces de canalizar la energía de un pueblo derrotado a través de un cine radical y subversivo. No nos olvidemos tampoco de Kiyoshi Kurosawa (1955), culpable de aquella descorazonadora fantasmagoría cibernética que fue Kairo; Takashi Miike (1960), capaz de alternar lo mejor y lo menos bueno en su extensísima filmografía; Shinya Tsukamoto (1960), nada menos que el padre del cyberpunk nipón en live action; o incluso Hirokazu Koreeda (1962), sin duda el más clasicista de nuestro decálogo, pero igualmente interesado en captar las múltiples posibilidades dramáticas de un núcleo tan cambiante como la familia japonesa contemporánea. Todos ellos, en mayor o menor término, articulan sus imágenes en torno al ciudadano japonés situado en un contexto nuevo, lo cual es germen de reacciones extremas como la violencia, la incomunicación y la pérdida de valores tradicionales (o valores per se).

Paradójicamente, nosotros no pensamos que Hideo Nakata sea un director extraordinario, al menos en la medida en que lo son algunos de los citados anteriormente. De hecho, sus dos primeros trabajos, el filme de episodios cortos Curse, Death \& Spirit (Honto ni atta kowai hanashi: Jushiryou, 1992) y Ghost Actress (Joyü-rei/Don't Look Up, 1996), son muestras irregulares en el mejor de los casos, más allá de ciertas ideas bien ejecutadas y lo que sin duda es el principal activo del cineasta: la recreación de atmósferas. Ello, unido a que en la práctica era el único autor de género a inicios de los 90, haría que Koji Suzuki propusiera su 
nombre para dirigir la adaptación de su novela. Como explica Rafael Malpartida, la «simbiosis promocional de literatura y cine funcionó a la perfección», pues ambas obras se retroalimentaron hasta conformar un fenómeno de masas sin precedentes (Malpartida, 2010: 362).

En cuanto al ritmo, el director opta por imprimir una cadencia parecida a la del cine japonés tradicional, muy tendente a los pocos cortes, estatismo de la cámara, abundancia de planos medios y largos, o ausencia de travellings, en lo que a priori serían medidas contrarias al gusto del espectador medio occidental, «siempre más cerca de la acción que de la contemplación» (Moscardó, 2013: 86). Sin embargo, recursos muy bien utilizados en Ringu como la cuenta atrás que comienza justo después de visionar el video maldito, el carisma de los dos actores principales Nanako Matsushima y Hiroyuki Sanada- o la tensión in crescendo que Nakata consigue imprimir a su trabajo, contribuyen a suscitar el interés de prácticamente cualquier tipo de público desde el comienzo. Si además valoramos su bajísimo presupuesto -apenas un millón doscientos mil dólares- o el poco tiempo invertido en el rodaje -alrededor de un mes-, el mérito se multiplica exponencialmente. Por lo tanto, a pesar de lo dicho en el segundo párrafo de este epígrafe, Nakata fue un gigante inigualable en ese año de 1998, tocado por la varita de la inspiración y en un estado de gracia al que ya nunca volvería siquiera a acercarse.

\section{FAMILIA TRADICIONAL Y FAMILIA MODERNA}

En aras de entender las alteraciones implementadas por Nakata en su reescritura cinematográfica es esencial conocer las circunstancias familiares del director, un varón japonés de treinta y seis años que cuidaba de sus dos hijas mientras su esposa se desempeñaba en el mundo laboral. Tal vez las paradojas de aquel posmodernismo familiar a la japonesa fueron las culpables de colocar a un onryo $\bar{o}^{-2}$ femenino donde hasta entonces hubo una entidad sobrenatural hermafrodita $y$, sobre todo, una protagonista divorciada, Reiko Asakawa, en lugar del genérico personaje principal del libro, un periodista masculino sin más.

Obsérvese ahora la manera en que el cineasta coloca al padre de Sadako como asesino de su propia hija en sustitución del Dr. Nagao, gesto inmejorable si se busca derruir el ideal confucionista. O si no, la canónica familia expuesta por Suzuki en contraste con la pareja separada en el caso de Nakata, cuyos integrantes son el reflejo de un Japón enfrentado a diversas paradojas de índole social y cultural. Estimamos a bien centrarnos sobre todo en el mayor protagonismo alcanzado por la mujer,

\footnotetext{
${ }^{2}$ Se trata de un yürei de mayor poder y ansias de venganza.
} 
algo manifestado positivamente desde luego en su inserción laboral, pero que a su vez genera un vacío del cual emanan individuos potencialmente desequilibrados en un plano cívico, social e incluso psicológico. No es tan extraño: tecnología donde antes existía tradición, matrimonio tradicional en decadencia, mujer periodista en un mundo de hombres y un niño de apenas siete años, Yoichi Asakawa, que vuelve solo del colegio o se prepara la comida por su cuenta en una clara muestra de desatención por parte de sus progenitores. No dudamos ni un momento de que el hecho de haber visionado el video maldito es una causa directa del descuido fraternal de Ryuji, tan centrado en la universidad y su amante adolescente, y de Reiko, consumida por sus trabajos de investigación. Otra cuestión distinta es definir si la irresponsabilidad de descuidar al niño es una medida gratuita o no.

Bajo nuestro punto de vista es más bien la solución radical a un problema imprevisto, la separación, que sin duda induce a la madre a seguir con su trabajo básicamente por dos razones: autoafirmarse como mujer dentro de la nueva contextura nipona y mantener económicamente a su hijo. De esta forma sería adecuado suponer que la protagonista padece el prurito de la maternidad, aunque no pueda ejercerla convenientemente, tesis que queda de sobra demostrada cuando Reiko abraza el cadáver corrupto de Sadako e un gesto a medio camino entre el cariño y la compasión, sabedora de todos los tormentos por los que había pasado en vida. Es ostensible cómo el hecho de vivir en primera persona la metamorfosis social de Japón hizo que Nakata plasmara esas inquietudes en su trabajo más reconocido.

Nada de lo anterior es observable en el hipotexto de Suzuki, donde los roles ejercidos por la mujer e hija de Asakawa se acotan a un perfil clásico e irrelevante. Si acaso podemos admitir que el recurso estimula el dramatismo de la cuenta atrás - pues recordemos que ambas cayeron bajo el círculo de Sadako-, pero al mismo tiempo evidencia la endeblez y vulnerabilidad de los personajes femeninos dentro del universo literario.

\section{FEMALE AVENGER Y FANTASMA VENGATIVO}

Hasta ahora sabemos que la ira sin fin de Sadako no acaba con el hallazgo de su cadáver. Comúnmente los onryō o yürei descansan en paz cuando acarreaban la caída de su asesino, la persona que los había agraviado en vida, o bien cuando eran bendecidos por un bonzo. El cliché llega hasta tal punto que ciertas versiones de Tokaido Yotsuya finalizaban con Oiwa alcanzando la iluminación tras la muerte de su esposo. Así las cosas, ¿cuáles son las diferencias entre el espectro de The Ring y los anteriormente aparecidos en la narrativa japonesa? No sería descabellado plantear la exhumación de Sadako como una metáfora de la lucha «neogeneracional» contra los traumas clásicos japoneses (Olivares, 2005: 79), 
enterrados y reducidos al propio fuero interno del individuo, pero ahora enfrentándose a esos nuevos grupos humanos que en parte rompen con la historia anterior. Y uno de esos colectivos es la mujer, consciente de la mejora de su situación social, aunque igualmente ansiosa por equipararse al hombre en términos absolutos. En este sentido la escena donde Shizuko es entrevistada por una multitud de periodistas es muy válida para analizar la conflagración entre géneros mostrada por Nakata.

Si prestamos atención nos percataremos de que entre los reporteros no hay ni una sola mujer, luego el autor desea potenciar la diferenciación básica entre ella -la madre de Sadako- y ellos -los periodistas-; en la historia, madre e hija representan una evolución peligrosa para el hombre, puesto que sus poderes mentales amenazan con ponerlo en peligro, pero alegóricamente subyace el miedo masculino a perder la situación de preeminencia que ha disfrutado a lo largo de la historia. De ahí viene la actitud timorata de los entrevistadores, enfrentados a lo desconocido al igual que el hombre de showa vio cómo su preciado status se veía cada vez más cuestionado por el ascenso femenino. Pero al fin y al cabo la situación no acaba de invertirse; estamos tan solo ante un amago que quizá libera parcialmente a la mujer, pero que a la vez la sigue sometiendo de una forma inconsciente a una inercia de casi diez siglos de tradición.

Ahora pensemos en el asesinato de Sadako y su confinamiento durante treinta años en la oscuridad de un pozo ${ }^{3}$. Sería incluso básico comparar esta desmedida condena con el histórico enclaustramiento de las japonesas, aunque nosotros en ningún caso dejaremos de ejercer tal paralelismo. Y es que Sadako, a diferencia de la mayoría de cuentos tradicionales, busca venganza, pero no al estilo selectivo de Oiwa, sino mediante una cólera irracional que devora a cualquier individuo que contacte con ella. Esto perseguiría la destrucción del sistema actual, el mismo que ha maltratado tradicionalmente a las mujeres y que posibilitó su cruel destino. Dicho de otro modo, el onryō de Nakata representa el deseo de equiparación femenino respecto a lo masculino, aunque ello signifique la destrucción de las estructuras actuales. Lo anterior convierte la figura del fantasma en una female avenger, concepto conocido de forma parcial en el kaidan, y sin embargo aquí desmedidamente potenciado. Al fin y al cabo el desagravio no llegaría con el castigo al asesino, al

\footnotetext{
${ }^{3}$ Durante la autopsia desarrollada en Ringu 2 se determinó que Sadako tan solo llevaba fallecida dos años, un prodigio sin duda alcanzado gracias a sus poderes sobrenaturales. Como mínimo es inquietante pensar en el odio acumulado durante aquel tiempo en el subsuelo, origen de un mal que amenaza con destruir a la humanidad, al menos tal y como la conocemos.
} 
maltratador o al amante que no corresponde, sino con la desestructuración de la maquinaria que ha originado tales individuos ${ }^{4}$.

Muy probablemente el lector desconozca que más del $80 \%$ de los espectros japoneses aparecidos en su narrativa son femeninos. Estamos ante un claro mecanismo exorcizador, una queja codificada tras un manto de fábulas emprendida a través de alguien irreal, el fantasma, que a su vez consigue con sus acciones post mortem aliviar la inacción del grupo al que representa: las mujeres (Míguez Santa Cruz, 2016: 347). De modo que la feminización anatómica de Sadako en el filme, abandonando su anterior naturaleza hermafrodita, supone una absoluta incrustación en el relatario fantasmático nipón. Por lo tanto, la anomalía genital del personaje literario ahuyentaba cualquier tipo de vindicación de género, más allá de otros detalles observables a lo largo de la novela, como son la condescendencia con la que en general son tratados los personajes femeninos o, como ya dijimos anteriormente, su rol secundario: verduras.

- Ha llamado la inmobiliaria, dijo Shizu mientras seguía cortando

—Y qué les has dicho?

- Les he dicho que mi marido no estaba en casa.

Siempre decía lo mismo... mi marido no está en casa o tengo que hablarlo con mi marido. Shizu era incapaz de decidir nada... epodría mi mujer valerse por sí misma cuando yo muriera? (Suzuki, 2003: 169) ${ }^{5}$.

Con todo, podría haber quien observe en el anterior fragmento una manera de visibilizar algunos de los problemas sociales existentes en el Japón de los 90, pero nosotros más bien pensamos que Suzuki se limitaba a registrar en su novela un comportamiento simple y llanamente consuetudinario en su país. Sumémosle la reflexión de Asakawa justo después de que su familia viera la cinta maldita: «sentí ganas de pegarle a mi esposa»; o el papel de mujer florero desempeñado por Mai, quien únicamente existía con el objetivo de realzar la envidia de Asakawa hacia Ryuji y servirles a los protagonistas masculinos sus tentempiés. A pesar de lo anterior, no buscamos emitir ningún tipo de crítica negativa sobre los subtextos del Ringu literario, puesto que Koji Suzuki, al igual que en otros

\footnotetext{
${ }^{4}$ No puede pasar desapercibido que muchas de las mujeres muertas por Sadako se conviertan en onryō (por ejemplo, Tomoko), mientras que los varones parecen quedar en una especie de limbo. Así fue el caso de Ryuji, que se apareció ante su hijo y su novia en el final de Ringu 2 para ayudarlos a escapar del pozo de Sadako.

${ }^{5}$ Todas las traducciones de la versión inglesa de la novela son propias.
} 
de sus trabajos, prefirió perseguir un afán eminentemente narrativo en vez de agitar conciencias.

Respecto a por qué el escritor introdujo como antagonista de su historia al fantasma de un hermafrodita, no somos capaces de proponer ninguna razón de peso, salvo que quisiera dotar a su personaje con el don de la excepcionalidad. De hecho, en cierta parte del libro Asakawa reflexiona sobre cómo el sistema binario del universo (dios/demonio, luz/oscuridad) en su origen hubo de ser perfecto, esto es, formado por una esencia única y sublime (Suzuki, 2003: 200). Sadako no dejaría de ser el epítome de esa idea, hombre y mujer en uno solo, rasgo físico extraordinario como superficie de su verdadera singularidad: la capacidad extrasensorial.

\section{J-HORROR Y TERROR NEUTRO}

Como decíamos al principio, desde su mismo estreno Ringu pasó a ser un incuestionable hito del género de terror cinematográfico. A priori esto hubiera sido improbable si consideramos la gran especificidad folclórica de la cinta, pero es obvio que aquel lenguaje estético impresionó a los espectadores más allá de cualquier determinismo étnico o cultural. Uno de los aspectos visuales más cautivadores fue el uso del cabello como fetiche del horror, aunque es justo reconocer que el filme de Nakata no fuera pionero en este sentido, sino más bien el que proyectara su popularización en el resto del mundo.

En la película la función del pelo es similar a la que tendría una máscara ${ }^{6}$, pues casi en todo momento esconde tras de sí el rostro de Sadako. Si nos detenemos un segundo llegaremos a la conclusión de que ocultar la naturaleza física del monstruo es si cabe más aterrador que mostrarla sin reservas, y no es extraño que durante gran parte del metraje nos cuestionemos cuán horrible podrían llegar a ser aquellos rasgos faciales. Es más, tan solo al final de la narración se podrá apreciar uno de los rasgos de Sadako, ese ojo ciclópeo y tan deforme que incluso potencia la contradictoria ansiedad de imaginar el resto de facciones en conjunto. Ya en la secuela, la cara del fantasma se nos muestra con todo lujo de detalles; aunque terrorífica, no deja de ser la encarnación de un temor hasta entonces estrictamente psicológico y, por tanto, resulta bastante menos compleja.

Yendo a una justificación antropológica o lingüística, debemos apuntar que el término pelo en idioma japonés suena exactamente igual que el vocablo dios (kami, 神, 'dios'), aunque sus kanjis sean distintos (kami, 髪,

\footnotetext{
${ }^{6}$ En el kabuki muchos espectros ya aparecían con el cabello cubriendo su rostro.
} 
'pelo'). Casualidad o no, desde antiguo existe la creencia de que el cabello disponía de un espíritu propio, razón por la que se le daba tanta importancia a su estética y tratamiento (Escobar, 2008: 129). Si nos atenemos a lo anterior sería más fácil razonar por qué algunos yürei son representados con un cabello gorgóneo y tentacular, prácticamente como si el pelo fuese un apéndice aparte del espectro, y sin embargo, bajo su control y dominio.

No por evidente dejaremos de subrayar el hecho de que el cabello largo sea un rasgo femenino en la mayoría de las civilizaciones. En Japón los hombres también solían dejarlo crecer en algunas etapas históricas, pero en ningún caso hasta el punto de las mujeres. Por consiguiente, que las lenguas negras de cabello largo constituyan un cliché tan reiterativo en el J-horror no hace sino corroborar su trasfondo vindicador, ya que esgrime uno de los atributos más evidentes de la feminidad como arma psicológica, e incluso física, contra sus víctimas.

Tampoco olvidemos la creencia generalizada de que el cabello sigue creciendo aún después de la muerte, razón por la que algunos espectros del cine japonés presentan cabelleras antinaturalmente largas. Si bien el tema se ha sugerido constantemente en la literatura o el teatro ${ }^{7}$, ha sido la imaginería del cine el factor relevante para consagrar el fenómeno. Un ejemplo es el episodio «Kurokami» ('pelo negro') de Kwaidan, cuya adaptación cinematográfica por parte de Masaki Kobayashi hace que el pelo emane más pavor que la misma esposa muerta del protagonista. En este punto también es insoslayable la espeluznante leyenda de la muñeca Okiku, en la actualidad guardada en el templo budista Mannenji de Iwamizawa por el "antinatural y constante" crecimiento de su cabello.

Como es de suponer, la gran mayoría de datos anteriores son comprobables en casi la totalidad de kaidan eiga, pero existen algunos casos donde se hiperboliza este factor hasta erigirlo en un pilar narrativo. En esa línea no podemos dejar de nombrar la saga de La Maldición (Ju-on, 2002) con especial remembranza de su secuela, La Maldición 2 (Ju-on 2, 2003). Pocos años después llegaron The Wig, la peluca asesina (Gabal, 2005), cuyo nombre deja poco lugar a la imaginación del lector; y sobre todo Exte: hair extensions (Ekusute, 2007), impregnada a conciencia de un tono cuasi-cómico por su afamado director Sion Sono, y por tanto más cerca de la parodia que del terror propiamente dicho.

Aparte, la relación entre la película de Nakata y el teatro kabuki era poco menos que inevitable. Al fin y al cabo fue este tipo de escenificación

7 Es interesante destacar las grandes cantidades de cabello falso usadas para impresionar a los espectadores de kabuki en algunas obras de temática espectral, como la célebre Tokaido Yotsuya Kaidan. 
el que terminaría por asentar las claves visuales del yürei, y Sadako se ajusta casi a la perfección a aquellos patrones originales. Tan solo deberíamos sustituir el clásico katabira blanco por un camisón del mismo color y largura, lo cual configura un aspecto casi indiferenciable desde la distancia, y el pelo liso en lugar del encrespado, más allá de que ambos estilos se acojan a una simbología similar.

Al kabuki también debemos agradecerle la tan característica forma de desplazarse de Sadako. De hecho la actriz que la interpreta, Rie Inō, se esforzó en remarcar sus movimientos y gestualidad facial al estilo de los onnagata $^{8}$, algo esencial para conseguir una actuación sensible en teatros enormes y con gran parte del público observando desde gran distancia. La cuestión relevante es que si apreciamos esa mímica impostada a pie de cámara y no a treinta metros obtendremos una sensación del todo antinatural en los ademanes. Un ejemplo es la expresión del ojo desorbitado de Sadako que aparece en la gran mayoría de portadas de DVD internacionales, desde luego típica en el kabuki, pero que al ser mostrada en plano detalle confiere un aspecto sin duda grotesco. Por si fuera poco, la conocida escena final de la TV se filmó ejecutando los acentuados movimientos de la intérprete hacia atrás, siendo posteriormente invertidos en posproducción para que la acción fuese apreciada hacia delante por el espectador ${ }^{9}$. El efecto motriz resultante es inverosímil para cualquier ser natural, pero se ajustaría al de una entidad foránea y turbulenta, que holla nuestro plano existencial tan solo para expandir su odio afligiendo a sus víctimas.

Tampoco hemos de olvidar la influencia del ankoku butō en los radicales movimientos del fantasma. Esta suerte de danza extravagante y consternadora fue concebida después de la II Guerra Mundial por los artistas Kazuo Ōno y Tatsumi Hijikata, quienes, aún traumatizados por haber sobrevivido a los bombardeos atómicos, decidieron inspirarse en los abruptos estertores de los quemados por las explosiones para crear un tipo de expresión escénica. Comúnmente, el baile contempla la alternancia entre ademanes lentos, bruscos e imaginativos, intentando expresar el sufrimiento padecido por el hombre expuesto a la arbitrariedad del cosmos. Ello, unido al maquillaje blanco de los artistas que representan la función, nos evoca particularmente el aspecto y sentimientos negativos inherentes a un alma descarriada como es el caso del onryō (Soler, 2008: 23).

\footnotetext{
${ }^{8}$ Actores kabuki que encarnan el papel de mujeres.

${ }^{9}$ Este recurso ya fue utilizado por David Lynch en las escenas oníricas de la habitación roja aparecidas en Twin Peaks.
} 
Como vemos, la adaptación cinematográfica de The Ring alberga tras de sí una enorme cantidad de referencias al folclore de su país. Las características son tan singulares que solo a partir de este filme se comenzó a tipificar el J-horror como un género reconocible, prácticamente como si Hideo Nakata hubiera sentado un canon: mujeres fantasma de cabello larguísimo, tez blanca, movimientos espasmódicos y ansias de venganza interactuando con un medio tecnificado. Ahora bien, ¿por qué no se reconoce a Koji Suzuki como el padre de este fenómeno aun siendo el autor de la novela original?

Si le echamos un vistazo a las apariciones fantasmales de la Sadako literaria ninguna es tan explícita como en su contrapartida cinematográfica. Es más, casi siempre conllevan un sutil enrarecimiento de la atmósfera, tal vez el descenso de la temperatura y, la mayoría de las veces, distintos tipos de sugestión. Así ocurrió con el olor a putrefacción que sirvió como mortal prefacio a Tomoko, la encarnación de su propia calavera ante Asakawa en la lóbrega humedad del pozo o la visión de Ryuji descomponiéndose ante el espejo justo antes de fallecer. Ahora bien, ninguna de estas manifestaciones lleva aparejada una descripción ni tan siquiera básica de Sadako, de modo que hemos de suponer que la proyección fantasmal es equivalente a su aspecto en vida: una mujer andrógina, bellísima y de gran altura, tal vez con signos de descomposición.

Nada encontramos, sin embargo, de las largas lenguas de melena negra o referencias al arte escénico japonés comunes a su transducción cinematográfica. Veamos ahora otros espectros creados por Koji Suzuki, en este caso pertenecientes a los relatos «Agua que se agita» y «Un crucero de ensueño» respectivamente:

En la sombra de los postes de hierro que sostenían el tanque se veían dos elementos similares a unos cordones que se balanceaban. Al forzar la vista, distinguió que una pequeña sombra oscilaba debajo del tanque. A Yoshimi le extrañó que desde su posición solo viera la sombra y no el objeto que la proyectaba. Una niña acurrucada debajo del depósito suspendido..., esa fue la imagen que se formó en la mente de Yoshimi (Suzuki, 2015: 31).

—Un niño está agarrando... la quilla.

Enoyoshi contuvo el aliento. De pronto, se formó en su mente la imagen del cadáver de un niño ahogado agarrado a la quilla.

- Se parecía a aquella muñeca, Dakkochan, que estuvo de moda hace mucho tiempo; aunque tenía la cara hinchada como un globo (Suzuki, 2015: 123).

Una simple sombra y un cadáver abotargado. En función de las vagas relaciones anteriores podríamos afirmar que el terror propio de Koji 
Suzuki, si bien se contextualiza en Japón, podría desarrollarse en cualquier otro país del mundo y no resentirse, puesto que carece de todos los códigos explotados en el J-horror salvo uno: la relación de los muertos con el agua. Arriba tenemos los fragmentos de su notable compendio temático Dark Water, del que llegaría a decir: «escribí este libro inspirado por el sonido de las olas que llegaban a mi habitación desde la bahía de Tokio» (Suzuki, 2015: 215). Pero más allá de la evidente influencia del océano sobre la creatividad artística de un isleño, la literatura de Suzuki es más psicológica que explícita, más reflexiva que visual. Se nota, incluso, la influencia del naturalismo francés que enseñó en la universidad de Keio, a través de una prosa limpia, sin artificios, unida al tono impersonal de la narración.

Por consiguiente, Suzuki se reserva el mérito de haber creado un notabilísimo thriller de investigación, casi detectivesco y aderezado con tintes sobrenaturales, aunque nunca el de haber sido el pionero en exportar un rasgo tan japonés como los yürei en su vertiente más canónica. Eso es patrimonio exclusivo de Hideo Nakata y su reescritura cinematográfica, copiada hasta el agotamiento.

\section{VIRUS Y TECNOLOGÍA}

La narrativa de terror a menudo usa elementos sobrenaturales como figuras metafóricas para advertir sobre otros tipos de peligros más reales. En ambas versiones de Ringu podemos observar esta dinámica, aunque los trasfondos sean tan opuestos como para dedicarles un análisis por separado. En el caso de The Ring de Suzuki es evidente la analogía entre la maldición de Sadako y la expansión de un virus, algo atestiguable en la misma reflexión final de Asakawa:

Tienes que enseñársela a alguien que no la haya visto nunca. Y a medida que la cinta se multiplicara, cada vez más copias serían necesarias. ¿Hasta dónde se expandiría aquel círculo? A la gente le afectaría su miedo a la enfermedad y aquella cinta de video apestada se extendería por toda la sociedad en un abrir y cerrar de ojos... En medio año casi todo Japón se habría convertido ya en portador y la infección se propagaría al resto del planeta... (Suzuki, 1991: 282).

En realidad, asemejar la maldición de un fantasma con una afección no tendría por qué ser tan extraño. De hecho, los virus son imposibles de observar en condiciones ordinarias y en varios momentos de la historia se han achacado los efectos de la enfermedad a posesiones demoniacas o fantasmales. Podríamos llegar a afirmar, incluso, que el virus habita en la frontera entre los seres vivos y no vivos, por su misma naturaleza nociva y microscópica. 
Pero decíamos que la figura del fantasma actuaría como alusión indirecta al virus, cuando en realidad la cuestión iría mucho más allá. Retrocedamos al momento en que Sadako es violada por el Dr. Nagao, recordémoslo, un enfermo de viruela. Nosotros pensamos que cuando la antagonista murió estaba contagiada de la enfermedad tras el contacto sexual. De alguna forma, Sadako fue capaz de asimilar el modus operandi del virus para sobrevivir - el contagio y la expansión- a la hora de imprimir sus vivencias en el tubo catódico situado encima de su tumba/pozo. Según lo visto, no sería muy descabellado afirmar que la Sadako de Suzuki es un espectro a medio camino entre el alma humana y una enfermedad propiamente dicha.

Ahora viajemos a finales de los 80 y sobre todo de los 90, época en la que Suzuki redactó The Ring. En 1982 los infectados de SIDA se podían estimar en unos cien mil a nivel global, aunque la cifra se multiplicó por trece a finales de esa misma década ${ }^{10}$. Es fácil suponer cómo los relatos sobre el padecimiento sin límites de los infectados por el VIH resultaban más espeluznantes que cualquier tipo de ficción. Hablamos de una pandemia mortal, difícilmente controlable y sin ningún tipo de tratamiento, un temor que sin duda se infiltraría inconscientemente en las narrativas coetáneas al fenómeno, cuando no se introdujeron a sabiendas con el objetivo de explotar ese desasosiego palpable a nivel planetario.

La visión del sexo como una práctica potencialmente peligrosa es otra de las posibles lecturas que podemos extraer. Recordemos la muerte de la pareja mientras mantenían relaciones sexuales en el interior del coche, o el origen mismo del poder alcanzado por Sadako: una infección transmitida durante un contacto sexual. También en el relato «Agua que se agita», perteneciente a la colección de cuentos Dark Water, la protagonista sentía una aversión absoluta hacía el sexo:

No veía ningún rasgo de su exmarido en su hija. Era un verdadero consuelo. Ni una sola vez había disfrutado de las relaciones sexuales. No conocía otra palabra que sufrimiento para expresar sus vivencias al respecto. Sin embargo, en el mundo se habla mucho de sexo. Tampoco podía entenderlo. Al parecer, una alta barrera insuperable la separaba de los demás (Suzuki, 2015: 22).

A priori este trasfondo conservador no suele ser común en la literatura japonesa por la misma naturaleza de su ética y moral religiosas, pero ya hemos visto unas páginas atrás cómo en Koji Suzuki existe una influencia occidental evidente en cuanto a cultura se refiere. En una línea similar se

${ }^{10}$ En línea:

https: / /www.elmundo.es/salud/2016/10/26/5810dd5046163f1a4f8b457b.html. 
pronunció el crítico Antonio José Navarro ${ }^{11}$ sobre It follows (David Robert Mitchell, 2014), aunque este tipo de conjeturas casi siempre dependa más de los ojos que miran que de cualquier aspecto científicamente tangible.

Respecto a Nakata, uno de sus logros visuales más reseñables fue extraer al típico yürei de los contextos clásicos e injertarlo literalmente en medio de la modernidad urbana. Y por todos es sabido que la tecnología recorre como venas invisibles las entrañas de las actuales urbes, ergo no sería extraño tropezar dentro del neo-kaidan con espectros en ascensores reemplazando a las antiguas encrucijadas de los caminos, en centros comerciales de alta gama en vez de bosques, en informatizados cuartos de baño en lugar de pantanos y, por supuesto, en aparatos electrónicos actuando como trasunto de los antiguos cementerios.

Y aquí es precisamente donde deseábamos llegar; la interacción del fantasma con el medio técnico o informático no es simplemente una cuestión coyuntural propia de la nueva época, sino que más bien responde a una necesidad crítica de advertir sobre los peligros potenciales de extralimitarse en el uso de las nuevas tecnologías. El recurso narrativo funciona a la perfección, pues posee la virtud de convertir objetos cotidianos con los que estamos familiarizados en iconos del horror, algo parecido a lo que consiguió Spielberg con la playa, espacio de ocio desvirtuado en Tiburón (Jaws, 1975), o antes Hitchcock con uno de los pocos distritos de relax que aún quedan para el hombre moderno: la bañera.

El sentido tecnofóbico de Ringu y el neo-kaidan responde a las mismas motivaciones que originaron Godzilla o todo el caudal de ficción cyberpunk en el manga y el cine. Después de todo, la relación entre los japoneses y el desarrollo siempre fue tumultuosa, en gran parte debido a su inmovilismo político y sus conocidas reticencias a relacionarse con el exterior. Cuando finalmente hubieron de abrir sus fronteras, los nipones asimilaron toda la tecnología a la que hasta entonces habían dado la espalda. Así evolucionaron de administrarse casi feudalmente en 1868 a ser la principal potencia electrónica en la década de los 70 del siglo XX, con compañías como Panasonic, Sanyo o Sony a la cabeza. Obviamente, el impacto sociológico de este fenómeno secular haría mella en el mundo de las mentalidades japonés, máxime existiendo episodios traumáticos como el de las bombas atómicas de por medio. Si a ello sumamos que tanto la literatura de Suzuki como la adaptación al cine de Nakata crecieron bajo el influjo del paranoide efecto 2000, terminaremos de evidenciar la

11 En su conferencia «Traumas y mutaciones del actual cine de horror norteamericano. Estado de la cuestión», para el I Encuentro multidisciplinar sobre el terror, la ciencia ficción y lo fantástico (Universidad de Málaga, 25 de octubre de 2017). 
connotación aviesa de la ciencia y el desarrollo "mal entendido" en este subgénero del yürei-eiga.

Naturalmente es fácil hallar múltiples paradigmas de lo anterior a lo largo de la película. Recordemos el suicidio de Shizuko, mujer tradicional y provinciana incapaz de resistir los estudios a los que se estaba sometiendo, en quizá una alegoría de las dificultades de aclimatación del pueblo japonés a la nueva realidad técnica; también las imágenes distorsionadas en las fotografías de quienes habían caído bajo la maldición de Sadako, a nuestro entender una clara alusión a la artificialidad y falsedad de unas instantáneas destinadas a impostar sentimientos de cara al exterior, más aún con el asentamiento de las redes sociales; aunque por encima de lo demás está la TV, piedra angular que vertebra la casa contemporánea, y que tanto mal puede acarrear a quienes la visionan $-\mathrm{O}$ escuchan-inconscientemente.

Según nuestra teoría tecnofóbica, cobra sentido que la escena de Sadako, irrumpiendo espasmódica desde la pantalla de la TV, sea exclusivo patrimonio del filme. Recordamos pocas imágenes más impactantes a lo largo del terror universal y una de las razones para justificarlo la ofrece el profesor Malpartida: el plano frontal levemente escorado del onryō saliendo del televisor nos implica a los espectadores como si fuéramos personajes mismos de la historia (2014: 115). Al fin y al cabo, nosotros también hemos visto la cinta, por lo que se genera un curioso juego de carácter metafílmico. Por el contrario, esto no sucede en los remakes coreano (The Ring Virus, 1999) y norteamericano (The Ring, 2002), en esa línea tan conocida de proscribir las pequeñas sutilezas de las originales en pro de distintos activos más rentables.

La crítica desde luego se proyecta en general sobre el avance tecnológico, pero también lo hace centrándose en la TV concretamente, como dice Julio Ángel Olivares, «de poder coaccionador y deshumanizador, instrumento de subyugación de masas, esclavizadora al dictado de las grandes corporaciones» (2005: 46). Y es que la sociedad nipona de posguerra se ha redefinido en torno a la caja tonta sin cuestionarse si las retransmisiones son beneficiosas, negativas o sencillamente irrelevantes. El hecho consumado nos habla de dos generaciones de japoneses que han vivido dependientes de la pantalla en sus diversas formas, degenerando a veces en casos extremos de observancia como sucede con los hikikomori, evolución natural de quien "vive" lobotomizado y absorto en la desinformación, que pasa a estar después exclusivamente hiperinformado. 


\section{EL FIN DE LA CUENTA ATRÁS: TRASVASE ENTRE LA LITERATURA Y EL CINE}

$\mathrm{Si}$ bien Ringu es una historia multi-formato eminentemente narrativa $^{12}$, su disposición artística nos habla de un trasfondo muy complejo. Se podría decir que detrás de lo obvio se esconde lo a priori inaprensible, en forma de parcelas de reinterpretación múltiples que hablan largo y tendido del carácter poliédrico de la obra. Ejemplo claro es el tono subjetivo de la cinta maldita que ejerce vertebrando cada relato, sin duda alguna un conjunto de imágenes codificadas y de interpretación más o menos abierta. El tono umbrío, gris y cenizo de esa unidad narrativa que es el metraje ficcional, consigue extenderse a cada página y fotograma del metraje real - es decir, el libro y la película en sí mismosapreciándose muy pocas excepciones o rara avis.

De especial mención es el culmen de esta progresión rítmica que supone el falso clímax del pozo, momento en que se halla el esqueleto de Sadako, simple resto putrefacto cuyo descubrimiento en nada condiciona la expansión de The Ring. Es muy interesante cómo Koji Suzuki y más tarde Hideo Nakata consiguieron relajar al lector/espectador haciéndole creer lo contrario, amparados en tantas y tantas decenas de historias donde el hecho de sacar a la luz los restos del maltratado supone el apaciguamiento del espíritu vengador.

Y ahora vienen los particularismos. Ringu es una historia narrada en dos lenguajes distintos: el literario y el cinematográfico. Suponer que uno está por encima del otro es un vicio extendido entre los consumidores, en gran medida por el superior y trasnochado estatus de la literatura respecto al cine. Dar por hecho que un libro es mejor que su adaptación cinematográfica (o viceversa) obviando el texto resultante, es similar a empecinarse en defender el sistema de programación Python en vez del Java, sin considerar la pericia del programador o la eficacia de su producto final.

Tampoco hemos deseado sumergirnos en el complejo océano de la narratología o la hermenéutica, pero es necesario valorar un par de aspectos a nuestro juicio esenciales a la hora de entender las eventuales disimilitudes entre el hipotexto y el hipertexto: a saber, la sensibilidad del creador y el tiempo necesario para consumir cada formato. En relación al primer caso, ya hemos visto cómo las circunstancias de Koji Suzuki fueron capitales a la hora de despojar a su obra del folclorismo típicamente japonés, del mismo modo que Hideo Nakata injertó parte de

${ }^{12}$ Pues hay películas que no tienen por qué serlo, en la línea marcada por el cine de David Lynch, David Cronenberg y sobre todo Terrence Malick, por poner tan solo algunos ejemplos. 
sus propias vivencias en su reescritura cinematográfica. Por otro lado, cuando el típico fanboy clama por la ausencia de algún personaje o cierto episodio en una adaptación fílmica, pasa por alto el hecho de que el cine está confeccionado para consumirse de una sola vez, mientras que la lectura de un libro permite un número de recesos al gusto del lector.

El ritmo, por consiguiente, constituye uno de los principales logros a conquistar tanto por parte del escritor como del cineasta/guionista, aunque en el segundo caso la cuestión adquiera incluso mayor relevancia a la hora de dirimir el éxito o fracaso de una obra. Entre los factores para explicarlo destaca la misma condición de quien acude a las salas de cine a visionar un filme, siempre más cercano al deseo de entretenerse que de consumir un producto cultural e intelectual. En otras palabras, si Peter Jackson consideró prescindible el capítulo de Tom Bombadil en su adaptación de El señor de los anillos por pensar que rompía la sinergia de una aventura recién comenzada, es igualmente entendible que Nakata, por ejemplo, descartase incluir el fragmento en que Shizuko se sumerge en el fondo marino para rescatar la estatua del asceta, razón por la cual quedó encinta de Sadako. Sencillamente, su inclusión desbarataría la estructura y el nuevo carácter impreso por el director a su transducción cinematográfica.

Es fácil encontrar a quien defienda la mayor relevancia del filme respecto al libro entendiendo su desmedida influencia ulterior. Fundamentos innovadores como el rol perturbador desempeñado por el cabello en la visualización del fantasma, o la grotesca y desasosegante forma de desplazamiento en los espíritus, conquistaron a los amantes de este tipo de películas sin necesidad de conocimientos determinados. De ahí la propagación masiva de copias literales proyectadas por casi la totalidad de industrias de cine asiático, por no mencionar el terrorífico fenómeno, en su acepción más negativa, de los burdos remakes estadounidenses.

Por supuesto, el calado de la cinta de Nakata ha resonado en mayor medida que el texto de Suzuki, aunque en loor de la verdad quizás estemos tan solo ante un dilema perspectivista. Si nos detenemos a reflexionar, el Ringu audiovisual triunfó por importar un nuevo y exótico resorte de espanto al resto del mundo, si bien dentro del mismo Japón el tratamiento verdaderamente inusual respondería al esquema de Suzuki, mucho más psicológico y desprovisto de tópicos visuales nipones. Entonces, ¿cuál de los formatos se merece un mayor reconocimiento? Si aún ronda esa pregunta por la mente del lector no hemos conseguido nuestro objetivo. En caso contrario, únase a defender el relato como un ente vivo, cambiante y sensible a las nuevas miradas surgidas con el paso del tiempo, pues nadie, ni el propio autor original, debería mantener cautiva una obra. 


\section{Bibliografía CITADA}

Escobar, Almudena (2008), «El cabello femenino en Japón», en E. Barlés y V. D. Almazán (coords.), La mujer japonesa: realidad y mito, Universidad de Zaragoza, págs. 129-154.

MalpartidA, Rafael (2010), «Dos estéticas del horror: Hideo Nakata y Takashi Shimizu (literatura, cine y remakes)», en S. Robles Ávila (coord.), Cine fantástico 100\% Asia, Universidad de Málaga, págs. 259-279.

MalParTida, Rafael (2014), Espectros de cine en Japón. Entre la literatura, la leyenda y las nuevas tecnologías, Gijón, Satori.

Míguez Santa Cruz, Antonio (2016), El fantasma en el cine japonés de posguerra. De rasgo folclórico a icono feminista [Tesis Doctoral], Universidad de Córdoba.

Moscardó, José (2012), Horror Oriental, Madrid, Arkadin.

Olivares, Julio Ángel (2005), The Ring. Una mirada al abismo, Madrid, Jaguar.

SOLER, Juan (2008), «Butoh (1959-2009). Medio siglo de rebelión en la danza», Acotaciones. Revista de investigación teatral, 20, págs. 23-46.

Suzuki, Koji (2003), The Ring, Londres, Harper Collins.

Suzuki, Koji (2015), Dark Water, Gijón, Satori.

Fecha de recepción: 06/08/2019.

Fecha de aceptación: 12/09/2019. 